ISSN 1852-2572

LA DENUNCI BAJO EL PERONISMO: EL CASO DEL CAMPO ESCOLAR

\author{
Dra. Flavia Fiorucci \\ Doctora en Historia por la Universidad de Londres \\ Master en Estudios Latinoamericanos e investigadora del CONICET \\ DOCUMENTO DE TRABAJO $N^{\circ} 41$
}




\title{
LA DENUNCIA BAJO EL PERONISMO: EL CASO DEL CAMPO ESCOLAR
}

\author{
Dra. Flavia Fiorucci
}

Doctora en Historia por la Universidad de Londres

Master en Estudios Latinoamericanos e investigadora del CONICET

DOCUMENTO DE TRABAJO N41

Conferencia pronunciada el 14 de mayo de 2011 en el ámbito del SEMINARIO PERMANENTE DE INVESTIGACIÓN de la Escuela de Educación de la UdeSA.

Coordinadora: Dra. Catalina Wainerman

DOCUMENTO DE TRABAJO N41

Agosto de 2012 
SERIE "DOCUMENTO DE TRABAJO"

ESCUELA DE EDUCACIÓN

Universidad de San Andrés.

Directora de la Serie: Dra. Catalina Wainerman

Responsable de edición: Lic. Lucía Vogelfang

Para obtener ejemplares de la Serie dirigirse a:

Universidad de San Andrés

Vito Dumas 284

(B 1644BID), Victoria, Pcia. De Buenos Aires

Ivogelfang@udesa.edu.ar

ISSN 1852-2572

Hecho el depósito que dispone la Ley 11.723

Impreso en Argentina - Printed in Argentina

Primera edición: Agosto de 2012 
La Serie "Documento de Trabajo" refleja parte de las actividades de la Escuela de Educación de la Universidad de San Andrés. Los documentos difunden conferencias dictadas en el ámbito del Seminario Permanente de Investigación de la Especialización y la Maestría en Educación con Orientación en Gestión Educativa, y del Doctorado en Educación.

El Seminario Permanente de Investigación tiene el propósito de estimular la producción y difusión de la investigación en el campo de la Educación. Tiene, además, el objetivo de familiarizar a los estudiantes de posgrado con la producción de conocimiento riguroso en el área. Entre los expositores se cuentan, fundamentalmente, investigadores formados y, eventualmente, expertos en planificación y política de la educación. También, egresados del Doctorado de la Escuela con sus trabajos de tesis terminados. 
Buenos días, agradezco mucho la invitación. Antes de comenzar quería señalar que no me dedico a la Historia de la Educación o, mejor dicho, que hasta hace poco no hacía Historia de la Educación. La semana pasada -fecha de edición del libro- terminé con un trabajo de investigación sobre los intelectuales y el peronismo ${ }^{1}$, en el marco de un grupo de historia intelectual. Y mi próximo proyecto tiene que ver con la historia intelectual, es un proyecto bastante ambicioso que consiste en hacer una historia cultural del normalismo o de la maestra normal. Por eso les pediré que me perdonen ciertos agujeros en algunas cosas que voy a decir y que me digan aquello que no sé porque ustedes conocen mucho mejor la escuela y el campo de la Educación que yo.

El trabajo que voy a presentar hoy es un trabajo bisagra, a caballo entre mis viejos y mis nuevos temas de trabajo. Primero les contaré un poco de qué se trata y después, en la medida de lo posible, compartiré algunas experiencias de investigación y cosas que creo que uno va aprendiendo cuando hace una investigación y que creo pueden servirles.

Hago un poco de historia: hice mi tesis doctoral y luego el libro sobre la relación entre los intelectuales y el peronismo. Ustedes saben que la mayoría de los intelectuales se posicionaron en contra del peronismo y ejercieron o expresaron de distintas formas un antiperonismo bastante visceral pero el campo intelectual obviamente está socialmente diferenciado. La propia idea de "campo" indica que hay un centro y hay márgenes en los que se sostiene y ese campo necesita de la proliferación de agentes mediadores. Con esta idea en la cabeza, empecé a buscar a estos agentes marginales. Era una especie de supuesto que tenía en la cabeza: que los intelectuales encumbrados estuvieron en contra del peronismo pero que los intelectuales mediadores -y yo entendía como intelectuales mediadores a los maestros- habían apoyado al peronismo.

¿Qué me hacía suponer esto? Que el propio régimen los había interpelado en esa forma porque la tarea que les había encomendado era, como todos saben, orquestar desde la escuela una campaña para generar consenso a favor del peronismo. Entonces, salí en búsqueda de estas figuras cuya voz es difícil de recuperar. Los intelectuales escriben libros, intervienen en la

${ }^{1}$ Fiorucci, Flavia (2011); Intelectuales y peronismo. Buenos Aires, Biblios. 
escena pública, pero sólo algunos maestros escriben y sus libros, en general, circulan por ese centro del campo intelectual.

Cuando uno trabaja con fuentes primarias -y esto es un aprendizaje-, los resultados que uno encuentra a veces no son los que uno se planteó al principio, se llega a caminos insospechados. Yo concretamente estaba buscando los expedientes de la Subsecretaría de Cultura y, en el medio de esta búsqueda, encontré un material que me permitía recuperar la voz de los maestros: los sumarios que el Consejo Nacional de Educación hizo a los docentes en la época peronista. Era un material que todo historiador sueña con encontrar, lo encontré de casualidad. Ahora es mucho más fácil acceder pero en ese momento fue una coincidencia. Estaba buscando otra cosa y apareció eso en el archivo que tenían catalogado de otra forma.

Cuando empecé a mirar ese material me di cuenta de que mi sospecha estaba mal, de que los maestros no habían sido los aliados intelectuales del peronismo o, mejor dicho, que el magisterio en bloque no había ocupado esa función, no había desarrollado ese rol y que además -y esto es lo que me gustaría compartir con ustedes- la pregunta estaba equivocada o era pobre.

En el material se asomaban cuestiones mucho más interesantes que se podían pensar. Si yo estudiaba ese material desde la pregunta sobre función y actuación como agentes mediadores, la respuesta sería muy pobre. Eso es algo que me parece que siempre hay que tener en cuenta y algo frente a lo que hay que estar atentos, calibrar nuestras preguntas y nuestros interrogantes en función de las fuentes y de los hallazgos que vamos haciendo a lo largo del camino. Estar atentos a que a veces hay que cambiar lo que uno pensaba encontrar.

Con el hallazgo de ese material se volvió muy evidente que no se podía pensar el campo escolar, el magisterio como aliado o enemigo del peronismo, como agente de transmisión o como agente de resistencia sino que había que pensarlo como el escenario de un conflicto de proporciones y resonancias que iban mucho más allá de la comunidad escolar. Cualquier conclusión que yo intentara delimitar dentro de esos moldes se me escaparía, quedaría corta. A través del material podía ver que la emergencia del peronismo había puesto en jaque la integración del mundo escolar -el de un grupo ocupacional, el magisterio- y también a las comunidades en donde las escuelas se insertaban, revelándome un conflicto del cual la literatura sobre el peronismo hablaba siempre tangencialmente. Se trataba del conflicto que se daba entre los vecinos y los colegas. $Y$ esto me obligaba a interrogarme y a repensar la antinomia "peronismo-antiperonismo" desde otro lugar porque era gente que vivía en el mismo lugar, gente que uno podía asumir compartía ciertos valores de clase, ciertos espacios de sociabilidad, y estaba en conflicto. Esto me permitía repensar hipótesis muy clásicas sobre el peronismo. 
¿Qué surgió del análisis de los sumarios? Como ustedes saben, los sumarios constituían y constituyen hoy el dispositivo que tiene la burocracia educativa para sancionar a los docentes que no cumplen con los roles que se han establecido para ellos. No sé si esto ha cambiado pero en la normativa de esa época el sumario se podía originar en una actuación de oficio, por prevención por parte de las autoridades y también por una denuncia. La denuncia podía ser hecha por cualquier persona "capaz y no imposibilitada por las inhabilidades absolutas". Y esto podía hacerse ante las direcciones de las escuelas, ante las inspecciones seccionales de las provincias y territorios y sus dependencias. Los únicos que ordenaban el sumario eran las autoridades del Consejo Nacional de Educación, incluidos los inspectores. En el caso de los empleados del Consejo Nacional de Educación -y esto incluía al magisterio-, la denuncia era "obligatoria y se consideraba falta grave el silenciarla".

¿Por qué se podía hacer la denuncia? Se podía denunciar a un colega por una conducta delictuosa, desarreglada o inmoral, por la transgresión de leyes y de reglamento, desobediencia voluntaria e incapacidad para el mantenimiento del orden y la disciplina, y por el atraso en la ciencia y en el arte profesional. Obviamente podemos suponer que esto generó siempre muchos conflictos, pero cuando observamos los sumarios del peronismo -los que están en el Archivo Intermedio del Archivo General de la Nación- se puede ver que muchos de estos sumarios se originan por el antiperonismo del miembro de una comunidad escolar, o sea lo que se denuncia es: "mi compañero o el maestro de mi hijo es antiperonista".

El primero de los sumarios de la época se hizo en febrero de 1946 -todavía no se habían hecho las elecciones, era el período de la campaña del peronismo- y se activó cuando las autoridades del Partido Laborista en Salta enviaron un telegrama al Consejo Nacional de Educación informando que el inspector de esa zona arengaba al personal docente en contra de Perón y a favor de la Unión Cívica Radical. Acusaciones de este tipo siguieron a lo largo de todo el período. Son numerosos los procesos administrativos, o sea los sumarios, que comienzan denunciando la militancia antiperonista de un maestro, un inspector o el director de una escuela. Otro ejemplo de sumario es, por ejemplo, el de la escuelo de Arroyito en Córdoba en el cual se incriminaba al director por realizar una campaña de desprestigio y saboteo de la obra de la Revolución Nacional -refiriéndose al peronismo-, e incitando a colonos y obreros a no colaborar con la obra del gobierno en ningún sentido. Lo que más abunda son imputaciones específicas -y que yo llamaría "menores"-: no respetar determinados símbolos, descolgar un retrato de Perón, ofender a través de expresiones, hacer comentarios en contra de Perón, gestos en contra de su figura. Recuerdo, por ejemplo, el conflicto entre una maestra y una directora porque la maestra realizó un discurso bastante exaltado sobre el 17 de octubre. Entonces la directora le 
reclamó que moderara el lenguaje que estaba utilizando. Ese discurso era muy exaltado y había en él mucha agresividad en la calificación de los antiperonistas.

Muchas veces a la denuncia del crimen, como si eso no bastara, los que denuncian agregan imputaciones de contenido no político, en general poco sustantivas. Les doy un ejemplo: al mismo director acusado de declarar que Perón se conducía como un dictador, acto seguido se lo denuncia también por alimentar al alumnado con fideos de mala calidad, raciones sin carnes y por actuar en forma poco caballeresca con las maestras al obligarlas a viajar en el acoplado de un camión. Esto sucedió en una escuela en Río Negro.

La prohibición que todavía estaba vigente de participar en política en cualquiera de sus instancias que establecía tanto el Digesto Escolar como el Estatuto del Personal Civil de la Nación también dio lugar a muchas denuncias. Según la normativa no se podía participar en política en ninguna instancia, pero las personas que denuncian interpretan que el peronismo está exento de esta prohibición. Muchas de las denuncias se basan en esta normativa. Los sumarios con más vericuetos, los más complicados son los que mezclan la cuestión política con la cuestión del honor y con la moral. Hay un sumario sobre el que escribí un artículo porque me parece que merece una mirada desde otro lugar, que es aquel en el que se acusa a una maestra de antiperonista y lesbiana. Doble crimen.

Obviamente el Consejo Nacional de Educación pondrá el ojo sobre el crimen de lesbianismo y no respetará el proceso -que en general se respetaba-: el Consejo Nacional de Educación considera que la mera sospecha es un crimen y entonces a esa mujer hay que separarla. Primero se la cesantea y después se la exonera del ejercicio de la docencia... Este es el sumario más largo que continúa por muchos años porque esta mujer siempre intentará volver. Era la directora de la escuela.

¿Quiénes eran los protagonistas que nos pueden brindar una cartografía de este fenómeno? Existe una bibliografía sobre el fenómeno de la denuncia en general en regímenes de rasgos al menos autoritarios. La denuncia se identifica siempre como un arma de los débiles. Es una comunicación espontánea -porque uno no está forzado a hacer la denuncia- que hacen los ciudadanos a poderes formales, puede ser frente a la Iglesia, el Estado, avisando la falta de otros ciudadanos. ¿Por qué se considera el arma de los débiles? Porque normalmente quien hace una denuncia lo hace porque no tiene por sí mismo la capacidad para compensar la falta. Las denuncias que estudio, que se dan en el contexto del peronismo, ocurren obviamente en un espacio muy definido que es el campo escolar e involucran a un campo profesional muy delimitado: el magisterio. Pero se dan en todo tipo de dirección: hay padres que denuncian al Consejo Nacional de Educación, a la directora o a una maestra; colegas que denuncian a otros colegas, directores a subordinados e incluso hay, como vimos, partidos políticos o autoridades 
políticas que denuncian la actuación de un determinado maestro, de un director o de un inspector.

Entonces yo creo que la denuncia en estos casos primordialmente instrumenta una guerra entre vecinos, entre iguales. Y por esto mismo creo que deja entrever los quiebres que la emergencia del peronismo produce en el orden local, en los espacios de la sociabilidad más micro aún cuando esté anclada en prácticas burocráticas que vienen de antes. Es decir que hay un diseño institucional que permite que este tipo de cuestiones se puedan llevar adelante.

¿Se pueden establecer patrones de lugares en donde se da este fenómeno? No. El fenómeno se repite en sociedades atravesadas por situaciones sociopolíticas muy distintas. La distancia más grande se da en capitales de provincia y se da en territorios nacionales. Hay muchas que se dan en los territorios nacionales, en la campaña rural, en la ciudad. Lo que es importante entender es que todas se investigan aún cuando tienen tramas inverosímiles. Esto tiene que ver con una práctica burocrática heredada y de larga tradición. Es decir que no hay correlación entre trama verosímil y atención estatal.

El peronismo respeta todos los tiempos y procesos del sumario -por lo menos en todos los sumarios que yo vi- salvo en el caso de la maestra lesbiana. Se sabe en el curso de la investigación -y eso lo pueden determinar los inspectores- que muchas de las acusaciones son fabricadas, ventilan prejuicios y detrás de ellas encubren motivaciones que no tienen que ver con lo político, al menos en la forma más inmediata. A veces los motivos aparecen muy claros a lo largo de la investigación sumarial. Por ejemplo hay un sumario que se le abre a un maestro de un pueblo en lo que en ese entonces era el Territorio de La Pampa porque se lo acusa de leer La Vanguardia, el periódico del Partido Socialista, de ser afiliado al Partido Socialista y de celebrar la frase "el aluvión zoológico" delante de la gente. Además se dice que es feo, que tiene labio leporino y un montón de cosas más -el Digesto Escolar prohibía el labio leporino, por considerarlo una deformación de la sífilis-. Como decía, al hecho de ser antiperonista se le agregan entonces otras acusaciones como que va a centros del hampa -en un pueblo en el que todo se sabe-. A lo largo del sumario se descubre que el autor de la denuncia es un padre analfabeto y que, en realidad, el que instiga a este padre -que no sabe qué firmó- a firmar la denuncia es otro maestro, un maestro que trabaja en otra escuela pero cuya mujer trabaja con este señor a quien se acusa y con quien se lleva mal. El acusado, en realidad, es el director. Pero pese a que se puede desestimar el contenido político de las imputaciones y ver que sacan a la luz problemas previos -que se llevaban mal de antes-, inquinas, problemas personales, es evidente que la recurrencia de este fenómeno, el hecho de utilizar el antiperonismo como un pretexto no se puede explicar de este modo. Hay que entender por qué se da este fenómeno. Obviamente el peronismo es una válvula de escape de cuestiones previas, pero ¿por qué? ¿Qué 
permite que esto sea así? Hacia el final retomaré esta pregunta que trataré de responder en la conclusión.

¿De qué depende qué pasará con estas personas? Hay un mito de que el peronismo siempre castigó a los desafectos, ¿no? Que en el peronismo, aquellos que no se ajustaban a la normativa serían castigados. Lo que yo descubrí al desandar los sumarios es que la suerte de estas personas denunciadas dependía casi exclusivamente de lo que decía el inspector. Así que los inspectores asumen el rol de árbitros morales y legales y mediadores del conflicto que inunda a la comunidad escolar. No es su rol difundir el mensaje político sino todo lo contrario, mediar en los conflictos que provoca la difusión de este mensaje político. Y lo que se puede ver es que revelan cierta aprensión por este problema que surge y frente a la difusión del uso de la práctica de la denuncia y que son muy cuidadosos a la hora de establecer sanciones. En gran medida lo que determina la suerte de la persona acusada es la evaluación de su capital social. O sea, el sumario convoca voces: se entrevistaba al policía, a los padres, al portero, a todos, y si la persona era querida en su medio no era sancionada aun cuando se supiera que militaba en el partido radical o en el partido comunista.

¿Por qué aparece esta cuestión con tanta insistencia? Creo que aquí hay una serie de cuestiones que intentaré abordar brevemente para no abrumarlos. Por un lado, existe una práctica burocrática de larga data, hay una institución que puede responder a este fenómeno -y que está diseñada para responder a este fenómeno- y, por otra parte, puede concebirse como una derivada y ahí es donde puede entenderse el porqué de este uso de la cuestión antiperonista, de ciertas enunciaciones del discurso político. En el imaginario del peronismo -hay muchos trabajos sobre esta cuestión-, el otro, el no peronista, es el antipatria. Eso es típico del discurso peronista. Entonces, exponer al colega no es un gesto de mero cinismo y de revancha sino que es también el arma de quienes asumen la tarea de vigilar y proteger la palabra peronista, que es, en este imaginario, la Patria misma.

No se puede, obviamente, diluir la denuncia por antiperonismo en un único efecto de enunciaciones discursivas, no sólo porque es espontánea -nadie les dice que denuncien a los antiperonistas- sino además porque estas personas se proyectan como custodios del peronismo, partícipes de primera mano de la construcción de la hegemonía peronista. Quienes recurren a la denuncia no lo hacen en virtud de la omnipotencia del Estado sino para compensar sus puntos más débiles. La denuncia permite que los ciudadanos asuman funciones estatales, y los proyecta como sensores de la cosa pública y no puede considerarse unilateralmente como una evidencia de la dominación política. Por el contrario, es una forma de ejercer la voz. Y no es casual que esto sucede en muchos lugares de los territorios nacionales porque, como saben, en los territorios no se votaba a nivel nacional y además son lugares donde tampoco 
existen los espacios de sociabilidad más típicos de la política como pueden ser los comités. Es una forma de ejercer la voz e interpelar al Estado.

Este fenómeno es posible porque hay una institución que puede responder y, por otro lado, que el fenómeno se haya dado con tanta insistencia entre los docentes no sólo tiene que ver con que la práctica era posible sino también con las expectativas de roles que se les habían otorgado a los docentes. Los docentes desde fines del siglo XIX o principios del XX tenían el rol de nacionalizar. Porque si el otro, el antiperonista, es el antipatria, hay que defender la Patria y los docentes de algún modo son afines a este imaginario de larga data.

Pero hay una condición que es necesaria para que esto suceda y es que los actores de algún modo ventilen sus conflictos: aquellos conflictos que habían estado latentes, esas inquinas, esos problemas personales porque el peronismo quebró la armonía del espacio en que vivían, quebró la cohesión. Alguien puede decirme: "bueno, era una cohesión frágil" pero sin embargo había un equilibrio. Y la denuncia -este tipo de denuncia por antiperonismo-nace y se desarrolla en un mundo social en el que los equilibrios de poder, lealtades e identidades previas, se han modificado en el interior de un mismo estrato social y en el interior de un mismo campo profesional. El material muestra cómo el peronismo lastimó la integración escolar, abrió brechas en el barrio, en el mundo rural, en el pueblo, allí donde antaño había grietas.

Lo que se puede ver claramente es que un nuevo orden social se impone y la denuncia busca recomponer ese nuevo orden social que la política está cambiando. Por ejemplo, hay un caso de un grupo de padres que denuncian a la directora en Jujuy porque maltrata a los alumnos peronistas. Estos padres no lo hacen solamente porque el peronismo los ha dividido aún más sino porque juzgan que su posición social ha cambiado. Entonces no es la campaña simbólica en la escuela la que produce estas micro-batallas sino que es otra cara de eso que Daniel James describió como la capacidad del peronismo de otorgar a la clase trabajadora un sentimiento muy profundo de solidez e importancia potencial nacional. Lo que cambió fue su propia representación del lugar que ocupan en la sociedad. El empoderamiento de ciertos actores que hace el peronismo significa que el régimen ha interferido en los equilibrios sociales previos. La denuncia es un síntoma, el uso de esta denuncia antiperonista es un síntoma de desajustes y hasta cierto punto puede ser leída como un mecanismo compensatorio y regulador del conflicto. Lo más notorio es que nos muestra una realidad paralela a las hipótesis más asentadas sobre el peronismo. No son los trabajadores contra los patrones los que vemos aquí en conflicto sino los trabajadores y los vecinos entre sí.

La denuncia se nos revela entonces como un fenómeno amorfo a partir de sanciones impredecibles porque se descubre que en muchos casos la denuncia ha sido fabricada y, en esos casos, se castiga a los responsables, y eso también obliga a matizar ciertas imágenes de la 
forma en que actúa el peronismo porque -como ya dije- los inspectores tienen total discrecionalidad para decidir, salvo en los casos en los que esté muy claro el tema de la moral y de lo sexual.

No se pueden recortar los objetivos de la denuncia por jerarquías escolares: no se ataca exclusivamente a los directores, sino que se ataca a los directores, a los maestros, a los inspectores. Además, la denuncia es obviamente afín a un discurso político autoritario, a uno maniqueo y a una burocracia disciplinadora pero también es instrumental a un sujeto que busca contribuir activamente a la construcción de la hegemonía peronista. No se puede ver sólo como dominación y reducirla a esto. Es necesario también considerar las características del Estado: receptivo, arbitrario pero no pocas veces mesurado y preocupado por los posibles efectos. Porque si se descubría que la persona acusada tenía un capital social muy importante en el lugar en que actuaba, no se hacía nada o se hacía una sanción menor -el traslado en vez de la exoneración. Esto concluía en el trabajo.

Ahora, hablando en términos de recetas y desafíos, les digo en primer lugar que me es muy difícil, me cuesta bastante reflexionar sobre mi propio trabajo. Creo que uno a veces está tan preocupado por lo que va a decir que hace el camino sin pensar. Voy a intentar transmitirles unas breves reflexiones.

La primera es estar atento a calibrar las preguntas, a calibrar los interrogantes en función de la fuente. Mi interés primordial no es la escuela, yo no hago Historia de la Educación, o al menos no hago un texto clásico de la Historia de la Educación en este trabajo. La escuela me sirve para pensar cómo el peronismo irrumpe en la sociabilidad de la vida que existe alrededor de la escuela. Me permite repensar el peronismo-antiperonismo en un nivel mucho más micro y de algún modo dialogar con hipótesis bastante conocidas sobre la antinomia peronismoantiperonismo. Al poner el foco sobre la escuela veo que, si bien es algo que es parte de un mito colectivo, ha sido muy difícil para los historiadores encapsular el tema de la vigilancia bajo el peronismo en situaciones concretas. Creo que todos hemos crecido con algún cuento de situaciones concretas, de ataques a personas comunes y ordinarias porque eran antiperonistas. Y lo que vemos claramente acá que en lugar de tener un gobierno supervisando a la población, tenemos una población que en muchos casos se supervisa y se censura a sí misma más que una constante vigilancia desde arriba. Las fuentes me permiten ver una vigilancia paralela y omnipresente que viene desde abajo y que se desarrolla en forma horizontal.

¿Qué conclusión podría sacar de esta forma de mirar la escuela que pueda compartir con ustedes? Diré algo tal vez un poco provocativo: lo que intento es que a la escuela se le puedan hacer preguntas más grandes que lo que tiene que ver con su quehacer concreto. La escuela 
encapsula mucho de lo que está pasando en la sociedad. Lo procesa de una forma diferente y digo esto sabiendo las complicaciones que implica, pero creo que si uno es cuidadoso la escuela nos puede mostrar mucho más que el quehacer educativo. Lo que hay que controlar es el tema de las reglas. La escuela es un contexto del campo escolar sumamente reglado y donde el tema de las reglas, creo, amplifica los conflictos.

Ahora quisiera hablar un poquito de la fuente. Los sumarios son materiales ricos y complicados, enormes. Son metros y metros y metros lineales e implican desafíos muy evidentes. EI más claro es el sesgo. Los sumarios, por ser una fuente referida a conflictos, pueden llevarnos equivocadamente a enfatizar el carácter conflictivo de lo que estaba pasando. $Y$ esto es cierto. No hay forma de que uno pueda escapar de esto. No digo con esto que no hay que abordar este tipo de fuentes porque nos conducirían a este problema porque estas fuentes nos permiten recuperar voces que de otra forma sería muy difícil escuchar. Nos permite recuperar bastante crudamente la voz de los maestros, la voz de los vecinos. Así como yo hice este recorte sobre el tema de la denuncia, hay miles de preguntas que se podrían hacer a esta fuente entre otras, por ejemplo, el tema de las relaciones de la escuela con la comunidad porque los sumarios no sólo traen la voz de los maestros sino -como dije- la voz de los vecinos, la voz de los padres, la voz del juez de paz. Entonces me parece que, controlando esta cuestión y siendo muy atento a las otras cosas que están pasando, es una fuente que no se puede soslayar.

Ahora voy a ser un poco abogado del diablo de mi propio trabajo y voy a decir algunas cosas en las que yo creo que me equivoqué, que hacen que todavía no haya terminado y que me obligan a volver al archivo aunque no quiera. Yo recorté el tema del antiperonismo que son metros y metros lineales e hice una muestra, una muestra totalmente aleatoria. Pedí que me dieran los dos primeros metros del principio de cada año -porque están divididos por año-, dos metros del medio y dos del final. Un error muy grave que cometí y del cual me arrepiento mucho es no haber tomado nota de todos los sumarios que no tenían este tema en el centro. Sé que eran mayoritarios pero hay también sumarios por violaciones, hay sumarios por estupro, hay muchísimos sumarios por cuestiones de castigo corporal que aunque estaba prohibido por la ley 1.420 seguía vigente. Hay unos sumarios sobre todo, y yo no tomé nota de eso. Tomé más o menos pero no fui sistemática. Así que si alguna vez quiero compartir este saber, tengo que volver al archivo porque no puedo contestar una pregunta muy simple que es cuántos sumarios -al menos en porcentaje de la muestra- respondían a esta cuestión y cuántos no. El problema es que soy una sola persona, no tengo un equipo de trabajo y es un material que tal vez debería ser abordado con un equipo. En mi defensa suelo decir que es un trabajo más de tipo cualitativo pero asumo recurrentemente este problema. Y me pregunto: ¿cómo pude ser tan tonta? Esta es quizás una cuestión muy nimia pero quiero transmitirles que -para no volver 
al archivo- sean lo más sistemáticos que puedan. Saqué fotos, pero eso no alcanza. Ahora aprendí que hay que ir con un cuadernito. Volví alguna vez al archivo e hice el trabajo sistemático para uno de los años, y cuando me preguntan intento responder con ese dato, pero es complicado.

Otra cuestión que creo es importante compartir e importante también para reflexionar es cómo hice esto y cómo elegí hablar de esta cuestión. Podría haber hablado de montones de cosas, pero de algún modo sistematicé esta cuestión de la denuncia. En primer lugar, yo hice un camino hasta poder sistematizar esta cuestión porque ingresé a este tema sabiendo muy poco de la escuela. No conocía las reglas y qué significaba la denuncia. Pensaba que se trataba de un fenómeno nuevo. Es difícil cuando uno ingresa a un tema nuevo cuyos contornos no controla. Por ejemplo, yo no sabía que el Digesto Escolar establecía que el sumario se podía iniciar por una denuncia y que la denuncia era obligatoria. Entonces el trabajo fue andando un camino hasta que descubrí eso y hasta que me di cuenta que era una práctica que existía.

¿Cómo llegué a sistematizar esta cuestión? Fui sistematizando el tema de la denuncia a través de lecturas y trabajos que no tenían que ver con la Educación. Sobre todo cuando me topé con el caso de la maestra lesbiana, me pregunté cómo podía empezar a pensar estas cosas. Y los textos de Historia de la Educación no me hablaban de esto. Busqué entonces caminos alternativos y empecé a sistematizar este tema estudiando las acusaciones de brujería. $Y$ luego a partir de ahí llegué al tema de la vigilancia en regímenes de rasgos autoritarios. Me inspiré mucho en trabajos sobre el consenso en la Alemania nazi. Y a partir de ahí llegué al tema de la denuncia. No fue un camino obvio, no me fue muy fácil escribir esto. Fue bastante complicado y tortuoso hasta que pude como darle un cuerpo metodológico y hasta que llegué a los trabajos sobre la denuncia en la Alemania del Este, en la Revolución Francesa y en Rusia.

Quiero decir con esto que a veces, cuando uno hace un trabajo de investigación, tiende a leer lo que pertenece a su pregunta y por ahí la inspiración no viene por ahí. Para la inspiración hay que escaparse de eso porque si no, además, uno vuelve a preguntar lo mismo que los otros, vuelve a abordar el material de la misma forma. Yo siempre miro a ver qué están escribiendo en otro lugar sobre temas similares, cómo piensan en otros lugares esta cuestión. Espero haberles compartido la cocina de mi investigación.

\section{PREGUNTAS}

Pregunta: ¿Cómo fueron el acceso al archivo intermedio, el acceso a las fuentes, a la información de que ahí estaba? ¿Y cuáles fueron las herramientas para trabajar en el archivo? 
Respuesta: Yo había hecho mi tesis doctoral sobre los intelectuales y el peronismo, cómo los intelectuales leyeron en ese mismo momento el peronismo, qué pasó, cómo actuaron. $Y$ pensaba que eso no estaría completo si no escribía un capítulo sobre la política cultural del peronismo. Después de hacer la tesis, me dije que el libro tiene que tener eso. Entonces me puse a investigar sobre eso. El peronismo crea una Subsecretaría de Cultura que no existía, sí existía una Comisión. Y casi todo el material del archivo está en la Biblioteca del Maestro porque dependía del Ministerio de Educación que se crea en ese entonces. Yo busqué allí los expedientes pero nunca pude llegar a los expedientes en la Dirección de Cultura. Yo leía en el Boletín insinuaciones de que ciertos proyectos culturales del peronismo habían provocado conflictos. Y quería ver eso porque el peronismo tuvo un proyecto muy importante que consistía en llevar cultura al pueblo para lo cual arma un tren cultural que iría a las provincias llevando cultura. Sospecho que en algunas cosas eran demasiado modernos o conflictivos para ciertos lugares. Y por alguna cuestión nunca encontré esos expedientes. Una aclaración. La tradición de los archivos en la Argentina es muy mala. Entonces yo preguntaba a todos los empleados del Ministerio “¿dónde puede estar esto?” Y me mandaron a hablar con un funcionario...

Pregunta: ¿En el Ministerio de Educación estabas ahí o en la Secretaría de Cultura?

Respuesta: Yo estaba en la Secretaría de Cultura. Todo esto está en el Centro de Documentación del Ministerio de Educación. Me dijeron que hablara con un funcionario, que él sabía dónde estaban esos expedientes. Fui a hablar con él y él me dijo que estaban en el Archivo Intermedio, que los iban a tirar pero que él los había enviado al Archivo Intermedio. Entonces fui al Archivo Intermedio pensando que allí encontraría esos expedientes. Y en el Archivo Intermedio me dijeron: "Bueno, es esto". Y me entregaron unos paquetes atados, sucios. No era lo que yo buscaba pero tampoco podía dejar pasar eso. Cuando empecé a leerlos me dije tengo que trabajar con esto. Y nunca encontré los expedientes de la Dirección de Cultura. No sé qué habrán hecho con ellos...

Pregunta: Quizás alguien los que quemó...

Respuesta: Mi hipótesis es que esas cosas no se queman. Nadie sabe dónde están. Son materiales complicados. Encontré por ejemplo un sumario hecho a una maestra por lesbiana y la arbitrariedad con que van a actuar contra esta persona es terrible... No estoy diciendo nada anacrónico en el sentido de que en ese contexto a una persona que era lesbiana, a la que se 
acusaba de tener amores con la portera, se la desplazaría si eso se sabía. Lo que digo es que no se respetaron los pasos del sumario.

Los sumarios continúan en la época de la Libertadora, y se revisan porque la Libertadora reincorpora a todos los maestros que han sido exonerados en teoría por el peronismo. La Libertadora revisa, no incorpora sin revisar. Hay un anexo en donde se ve lo que pasa: la Libertadora es mucho menos respetuosa de los pasos del sumario que el peronismo. Esta mujer obviamente no vuelve a ser reincorporada. $\mathrm{Y}$ los acusados de comunistas tampoco vuelven a ser reincorporados por la Libertadora.

El archivo está ahí. Para los que tengan que hacer tesis: el archivo va para adelante y para atrás. Una de las cosas que pienso hacer para la historia cultural del normalismo es ver el ejercicio de la docencia y una de mis fuentes va a ser esto.

El Archivo Intermedio es un archivo que se suponía iba a ser como un archivo donde se iban a procesar las cosas que iba a pasar al General pero quedó ahí y gran parte del siglo XX está en el Archivo Intermedio. Lo cual yo creo que es una suerte porque la gente que maneja el Archivo Intermedio es muy buena y te dejan acceder al material bastante fácilmente. Ahora quiero revisar para mi nuevo proyecto el Archivo de las Escuelas Normales y eso está en un depósito del Archivo General de la Nación y como está en ese depósito no me lo querían dejar ver. La ley dice que pueden tenerlo en proceso un tiempo pero después tenemos derecho a verlo. Al final hemos llegado a un acuerdo y se lo van a pasar al Archivo Intermedio. Si a alguno le interesa trabajar con este archivo, allí hay material para escribir pilas de tesis, pilas de libros porque se le pueden hacer millones de preguntas a esto.

Pregunta: ¿Cuáles fueron las dificultades para trabajar sobre las fuentes?

Respuesta: La fuente es abrumadora: son metros y metros lineales. Hay otras dificultades...

Pregunta: ¿Por cada sumario es un expediente?

Respuesta: El de la maestra lesbiana son dos carpetas enormes, son larguísimos. Y la otra dificultad es que no sabés si están todos. Lo de los porcentajes nunca se podría responder a ciencia cierta porque la General no sabe. Hay un dato: todos los años son metros y metros lineales salvo el año 1953 en el que hay alguno que otro y yo creo que debe haber habido muchos sumarios porque fue el año posterior a la muerte de Eva y la campaña para generar con- 
senso en la escuela por el peronismo empezó en 1951. A partir de entonces tuvo que haber habido más conflictos y eso no está.

Pregunta: No están reflejados en los expedientes...

Respuesta: No, no están reflejados en la cantidad. Eso es una dificultad y es una de las cosas que yo uso para defenderme. Tampoco tiene mucho sentido hablar de porcentajes si no se sabe si ese es el universo. Y es una fuente difícil porque cuando uno trata de meterla en un molde algo se escapa. Yo recorté pero podría haber tomado otras cosas. Recorté esto porque venía haciendo una investigación sobre el peronismo. Pero me imagino que alguien podría hacer otro tipo de recorte temporal y hacer otras preguntase...

Alguien podría ver el tema del castigo en la escuela. Me parece que lo que más revela la fuente que podría ser estudiada de esa forma es cómo es la cotidianeidad de la escuela, algo muy difícil de recuperar y es lo que yo quisiera mirar hacia atrás.

Lo que también me sirvió para inspirarme es la gente que trabaja con expedientes legales. Miré muchos trabajos sobre eso a ver cómo lo hacían y para el tema de las cuestiones de faltas a la moral sexual en general la fuente principal que se usa son los expedientes judiciales. Lo que tiene de interesante esta fuente es que aparecen las diferentes voces porque en los expedientes judiciales en general hay mucha intervención de letrados y se pierden esas voces...

En cambio en éste -y esto es lo interesante de los sumarios- están los descargos de puño y letra de los maestros. Hay uno que hace su descargo que me parece genial: lo acusan de antiperonista, de ser un caudillo local y de tener mala ortografía. Entonces el inspector le señala en todos sus descargos con tinta roja las faltas de ortografía horrorosas. Y dice: "Tiene faltas de ortografía lo que se puede ver en su propio escrito". En los expedientes judiciales, en cambio, en general el que interviene, el que arma el relato es el abogado o es el fiscal el que arma las preguntas. Los sumarios son mucho más espontáneos, aunque no del todo...

Pregunta: Entiendo que tenías una cantidad de material escrito importante y tuviste que codificarlo o de alguna manera. Para codificarlo, ¿usaste algún Software?

Respuesta: No. Los historiadores venimos de un campo distinto. Leemos y tomamos nota. $Y$ yo ahora acabo de escribir mi primer trabajo sobre el normalismo y todo el verano me pasé leyendo las memorias de los directores de escuelas normales y tomé notas. Tengo ciento y pico de páginas de citas escritas. Metodológicamente por ahí no somos el modelo a copiar... 
por eso digo que metodológicamente quizás tengo un problema y lo digo, por ejemplo, por lo del porcentaje. Eso tiene que ver con la forma en que trabajamos. Me parece que si en este tipo de material se usa un Software se lo traiciona. Yo sacaba fotos, sacaba fotos a todo el sumario. Y después leí todas las fotos. Y tengo un cuadrito por cada sumario. Anotaba en el cuadro el inicio, cómo empezó, quién acusaba, quién era el acusado, qué acusación hacía, la fecha, el lugar, el resultado, la justificación, la reacción de la comunidad y la revisión por la Libertadora.

Pregunta: A lo largo de los textos, ¿no buscabas regularidades?

Respuesta: Sí. Lo que trataba de buscar es cómo había sido iniciado, quién lo había iniciado, quién había sido acusado, si una maestra, una directora, un padre o un vecino, de qué se lo acusaba. De qué se acusaba, además de antiperonista. La fecha, lo me permitió también ver cómo fueron creciendo. Lo que se ve es un gran crecimiento. Después empieza a haber un declive. Aunque eso es engañoso porque no sé si están todos ahí. ¿Qué sucede si hubo una mano que sacó un montón? Si la muestra es aleatoria deberíamos asumir que sí pero yo no estoy tan convencida. Después el lugar, las características de la escuela. Por ejemplo la de la maestra lesbiana es una escuela al aire libre, en Capital Federal que fue cerrada después de esto.

Pregunta: ¿En Parque Avellaneda?

Respuesta: Puede ser en Villa del Parque. Eso tiene algunas consecuencias porque la que denuncia es una visitadora de higiene. Esa fue mi sistematización. Y también tomé nota de la reacción. Algunas quedan muy confinadas y en otros casos, como por ejemplo en Gualeguay, se arma una huelga, el cura se pelea por la enseñanza del revisionismo en la escuela. Parece que hay algunos profesores y maestros revisionistas y hay un padre que trabaja en un periódico y hace una denuncia. A partir de ahí se empiezan a activar todos los mecanismos y hay una huelga del comercio local por el sumario porque se empiezan a sumariar a algunos maestros.

Pregunta: Son dos preguntas en realidad o varias. ¿Cuánto tiempo te llevó hacer el trabajo? ¿Estabas solamente dedicada a esto o trabajabas además? Esto tiene que ver con una cosa más operativa porque me parece que el trabajo es un trabajo muy grande, por un lado. $Y$ la otra pregunta es: en estos sumarios hay nombres de personas, ¿cómo es la cuestión ética 
cuando uno presenta el dato o presenta el informe? ¿Usás seudónimos? ¿Cómo juega esta cuestión de asociar al lugar, al nombre de la persona más allá que muchas seguramente ya no están?

Respuesta: Empiezo por la de los nombres. Vos firmás una especie de papelito en el archivo diciendo que no vas a usar los nombres. No se puede porque cuando involucra la moral no se puede usar el nombre entonces utilicé seudónimos. Capaz alguien pueda adivinar de quién se trata si sabe que esa persona fue directora en esa época en esa escuela. Pero los nombres no se utilizan porque ahí hay muchos registros de cosas muy sensibles.

Sobre cuánto tiempo me llevó. Yo estoy en el CONICET o sea que trabajo en investigación. Paralelamente estaba terminando el libro así que lo fui haciendo junto con el libro pero me llevó más de un año escribirlo. Fue un artículo que me llevó mucho tiempo escribir o sea que no me llevó el tiempo habitual de un artículo. Me llevó mucha lectura y mucho tiempo de ir rumiando. He escrito otros artículos por ejemplo sobre las bibliotecas en el peronismo: fui al archivo, encontré los datos sobre la gestión del peronismo en las bibliotecas y escribí el artículo. Fue más fácil. Este me resultó mucho más difícil. Además esta es como la cuarta versión, lo fui escribiendo y reescribiendo y todavía hay algunas cosas en las que sigo pensando.

Lo mandé a un Journal y me pidieron correcciones que tengo que hacer, algunas tienen que ver con que es una publicación de afuera y quieren algunas precisiones sobre el peronismo y tengo que escribir cosas sobre la escuela. Creo además que uno de los evaluadores interpretó mal porque cree que yo hago un trabajo sobre la escuela. A mí me parece que esto no es un trabajo sobre la escuela. Así que todavía tengo que hacer correcciones. Me llevó bastante tiempo. No fue un artículo que escribí en tres meses. No sé cuánto exactamente porque hace como tres años doy vueltas con el artículo y nunca termino la versión última.

Pregunta: Es un aliciente.

Respuesta: No soy ejemplo porque yo terminé mi tesis hace ocho años, y recién esta semana salió el libro...

Pregunta: Me das esperanzas porque yo la terminé hace cinco...

Respuesta: No soy el ejemplo porque escribí la tesis y reescribí el libro dos veces. Son formas. Mejor es hacerlo más rápido. 
Pregunta: Cuando estabas haciendo la presentación dijiste rápidamente que las reglas amplificaban los conflictos. Yo me pregunto en qué detectaste eso. Hablando de la escuela.

Respuesta: La regla, por ejemplo, de que no puedan participar en política. Los maestros son en general personas de cierto nivel educativo y eso genera fricciones. El tema de las expectativas de roles que se esperan de un maestro...

¿Por qué van a exonerar a esta señora porque es lesbiana? Esto quizás se debe a que se trata de una institución sumamente reglada donde se espera que ella sea un ejemplo y cualquier desviación, por mínima que sea, que en otros contextos no generaría este conflicto sí lo genera en la escuela. Hay tanto depositado en el normalismo y en la figura de la escuela normal que esto es una especie de clásico: se dan conflictos que por ahí en otros contextos se podrían procesar de otra forma. Pero en ese mundo se convierten en una violación y, muy rápidamente, en una trasgresión. No sé si responde. Pueden no adscribir...

Pregunta: Mi preocupación es respecto del impacto de las publicaciones en el mundo académico y en el contexto social. A mí me parece que toda moda de las bases me parece interesante para ver qué reacción genera en la comunidad académica y sobre todo en el contexto social. Es un tema que hoy está en agenda porque toda la lógica peronista impone una mirada muy provocativa al gobierno actual. Entonces me preguntaba cuando vos hablabas si estuvieran aquí determinadas personas no sé cuánto podrías avanzar en tu presentación. Entonces se me ocurrió pensar en cuál es el nivel de reactividad porque desde el punto de vista internacional creo que es baja pero no sé cuánto has conferenciado o presentado esto en el ámbito nacional y cuál ha sido la reacción. Porque si bien vivimos en una democracia sabemos que hay lógicas y hay ideologías que imponen cierto nivel de reactividad, ¿no?

Respuesta: No, en general no he tenido problemas. Siempre lo he presentado en contextos de historiadores, como un trabajo metodológico. Con mi otro trabajo el de "Los intelectuales y el peronismo" he tenido algunos encuentros complicados por algunas cuestiones que digo pero no de ese modo... Solamente una vez sufrí algo así como una impugnación muy fuerte de parte de una persona a la que no le gustaba más que nada no lo que yo decía sobre el peronismo sino lo que decía sobre el antiperonismo. Mi argumento en el libro básicamente es que no hubo militancia antiperonista entre los intelectuales, sí que hubo una estrategia de moderar el lenguaje...

Pregunta: ¿Tenés alguna idea de mediciones de consultas de publicaciones? 
Respuesta: No, no tengo idea.

Pregunta: A mí me parece que es un dato interesante ver cuál es el nivel de consulta que generan las publicaciones...

Respuesta: A veces me llama la atención porque recibo muchas consultas. Lo que pasa es que en general son sobre mi otra investigación que trata acerca de los intelectuales y el peronismo.

Pregunta: Porque de alguna manera uno escribe también para generar un aporte al conocimiento...

Respuesta: Sí, claro. El otro paper lo he circulado mucho y a éste lo he presentado también. En general he tenido buena reacción y puedo ver ciertas repercusiones que pertenecen a un mito colectivo, el del tema de la vigilancia. Yo misma crecí con ese mito. Mi mamá me contó una historia de chica: mi bisabuela era directora de una escuela y se negó a poner plata para el velorio de Eva. El cuento familiar es que se negó a poner plata, que llamó a todas las maestras y les dijo "ustedes tienen que poner plata, yo se los aconsejo, pero yo no voy a poner por principios" y que entonces la jubilaron de oficio y que por dos años no le pagaron el sueldo. Esta es la anécdota familiar, y es posible que haya sucedido, pero me resulta raro que no hubiera habido algún otro conflicto anterior que justificara que la hayan jubilado de oficio. Según mi mamá, mi abuela -que estaba separada- vivió esos dos años contrabandeando medias de nylon y cosas de nylon con el vapor de la carrera. Yo no sé si es cierto: mi bisabuela murió y nunca lo podré saber.

No sé cuánto se ha leído este trabajo pero en general responden bien porque encarna este mito, esta cuestión colectiva de que había una vigilancia bajo el peronismo y eso se puede ver claramente aquí y se ve en casos concretos. $Y$ eso simplemente permite decir que el antiperonismo era una máquina mucho menos perfecta que aquella que creó el antiperonismo o al menos que funcionaba mucho menos aceitadamente.

Yo uso la palabra "régimen". Llamarlo "régimen" implica ciertos supuestos y la mayoría de la bibliografía actual hoy sobre el peronismo trata de enfatizar una división entre la primera y la segunda presidencia de Perón porque la primera presidencia es de rasgos mucho menos autoritarios que la segunda. Hacen énfasis en los componentes contradictorios del peronismo. 
Todos los trabajos que estudian si el peronismo fue autoritario en algún aspecto demuestran también que en otras cuestiones tenían políticas muy liberales.

Yo no he hecho difusión porque se trata de un trabajo académico. Si la hiciera, seguramente me enfrentaría a otro tipo de intervenciones y reacciones. No sé si respondo más o menos lo que me preguntan.

Pregunta: A mí lo que me parece interesante de lo que planteás -en términos de la vigilancia del Estado- es el darle la voz a otros para asumir un rol de vigilancia. Esto es algo que no sé si estaba tan extendido antes, la idea de que cada uno puede hablar con el Estado y mostrarle lo que pasa. Me parece que esto sí es novedoso.

Respuesta: Sí. Hay unos pocos trabajos que estudian el material del Archivo de la Secretaría Técnica porque cuando se va a hacer el Segundo Plan Quinquenal se convoca a la ciudadanía para que haga propuestas que se incluirían en el Segundo Plan Quinquenal. Y ese archivo con las cartas de la gente -miles y miles de cartas- está disponible en el Archivo General de la Nación. Esta campaña se llamó algo así como "Perón quiere saber de qué se trata" y la gente escribía pidiéndole cualquier cosa. Había algunos incluso con dibujitos. Le piden desde una biblioteca hasta un nuevo teatro, una política nueva con respecto a todo lo que se les pueda ocurrir.

Pregunta: Hay una cosa de la que yo no he escuchado hablar, que es la motivación de escribir y publicar. Quería pedirte un lineamiento general porque creo que es muy interesante cuando uno tiene un trabajo poder ubicar cuáles son los clásicos del campo, dónde mandar un artículo, qué revista puede tener interés...

Si uno como estudiante de Maestría o de Doctorado quiere mandar un artículo a algún lugar, ¿qué recomendás? ¿Cómo eligir la revista? Yo no tengo muchas publicaciones y de las pocas que tengo el proceso de revisión ha sido muy duro, especialmente en journals internacionales. Un journal internacional es una "batidora" y a veces estás seis meses o un año sufriendo con las revisiones. Me ha pasado con una de las últimas publicaciones y siento que no hay orientación en esto. ¿Quién te enseña esto? ¿Quién te cuenta cómo es este proceso? Porque es parte de la diseminación del conocimiento. Cuando escuché que habías mandado el paper a un journal y que lo estaban revisando, entonces se me ocurrió preguntar porque me parece muy interesante conocer tu mirada desde esta experiencia de la publicación. 
Respuesta: No tengo una experiencia muy distinta a la tuya. La realidad es que los journals se toman un año y medio para contestarte, o dos años. Yo tengo una publicación en una revista local reputada y tardaron dos años en contestarme y me contestaron después de que le escribí al director diciéndole que era una vergüenza y que me dijeran si sí o si no. Es muy importante elegir el lugar. Yo soy Secretaria de Redacción de un anuario. Es una tarea complicada porque a los evaluadores les damos tres meses y muchas veces hay que apurarlos. ¿Cómo elegir? Depende del campo. En Historia lo más importante es si tiene o no tiene referato. Hay una jerarquía de revistas y se sabe que hay determinados journals o revistas en los que es más difícil publicar. En el campo de la Historia además hay que tener un libro...

Pregunta: ¿El libro es más que el artículo?

Respuesta: Y sí. No tener un libro pesa siempre como una espada de Damocles. Hasta que no se tiene un libro no se es historiador. Obviamente el CONICET cuenta la cantidad de artículos y es importante, $Y$ capaz que el CONICET pone más puntos a los artículos con referato pero en el campo hay que tener un libro. En otros campos disciplinarios, no...

Pregunta: No, en Salud son los artículos...

Respuesta: En Historia, lo que te define es tener un libro. El libro te apropia de un tema, te vuelve especialista. Hasta que no tenés un libro no pasaste de grado. Lo que te puedo decir es que los mismos inconvenientes que tenés vos los tiene todo el mundo. Capaz que ya no los tiene el Halperín Donghi obviamente. Yo trabajo en una revista y si Halperín Donghi nos manda un artículo no lo vamos a mandar a referato. Pero a todos los demás los mandamos a referato y yo a veces me enojo porque yo soy la Secretaria y entonces soy la que doy la cara y después de diez meses me preguntan si sé algo de un artículo y tengo que contestar que no. Lo que te pasa a vos a mí también me pasa. Yo tengo en este momento tres artículos en evaluación y dos de ellos hace más de un año. $Y$ no tengo ninguna respuesta... Y uno se pregunta qué hacer, si sacarlo o no. Pero ya pasó un año. Si lo mando a otro lado, va a pasar otro año.

Pregunta: Yo ahora estoy terminando la tesis y en este momento las publicaciones son muy importantes para aplicar a becas, es algo definitorio en un momento.

Respuesta: Yo he notado por ejemplo en el contexto local que el CONICET se ha puesto muy firme. Desde lo personal, siendo Secretaria de esta revista antes aunque rechazábamos 
artículos siempre llegábamos muy justos al número de artículos. Es una publicación de Historia Intelectual, es un campo muy chiquitito. $Y$ no nos llegaban suficientes artículos 0 al menos 0 una masa crítica de artículos que nos permitiera hacer una súper selección, los seleccionábamos de todas formas pero siempre llegábamos a los cinco artículos que normalmente publicamos muy justos. Ahora, en cambio, ya tenemos casi todos los artículos para este número y para el siguiente seleccionados. Eso quiere decir que hay más necesidad de publicar y la gente envía más y eso hace que todo demore más.

Pregunta: Hay más investigadores también.

Respuesta: Sí hay muchos más.

Pregunta: Ahora falta que aumenten los sueldos.

Respuesta: Sí.

Gracias por invitarme y escucharme. Espero volver cuando tenga escrito el libro sobre el normalismo -y que no me lleve diez años-. 


\section{OTROS DOCUMENTOS DE LA SERIE \\ "DOCUMENTO DE TRABAJO" DE LA ESCUELA DE EDUCACIÓN}

$N^{\circ} 1$ OIBERMAN, Irene Beatriz. La creación de un sistema de información educativa para la gestión. Mayo de 2001; 20 páginas.

$\mathrm{N}^{\circ} 2$ ABDALA, Félix. Los excluidos del sistema educativo argentino: resultados peliminares de una investigación. Septiembre de 2001; 14 páginas.

N³ GALLART, María Antonia. La escuela como objeto de investigación. Septiembre de $2001 ; 8$ páginas.

$N^{\circ} 4$ FISZBEIN, Ariel. Análisis institucional de la descentralización educativa: el caso de los países de Europa Central. Agosto de 2002; 14 páginas.

N॰5 CARUSO, Marcelo. La relación pedagógica moderna: cultura y política de la didáctica. Octubre de 2002; 21 páginas.

$N^{\circ} 6$ TEDESCO, Juan Carlos. Una política integral para el sector docente. Mayo de 2003; 11 páginas.

$N^{\circ} 7$ WAINERMAN, Catalina. Un siglo en los libros de lectura en la escuela primaria. Junio de 2003; 14 páginas.

$\mathrm{N} \circ 8 \mathrm{BEECH}$, Jason. El discurso de la era de la información y la educación en Argentina y Brasil. Noviembre de 2003; 16 páginas.

N`9 BAQUERO, Ricardo. La educabilidad como problema político. Una mirada desde la psicología educacional. Noviembre de 2003; 20 páginas.

N`10 GAINZA, Violeta. La educación musical entre dos siglos: del modelo metodológico a los nuevos paradigmas. Noviembre de 2003; 15 páginas.

N¹1 AGUERRONDO, Inés. Ministerios de Educación: de la estructura jerárquica a la organización sistémica en red. Junio de 2004; 13 páginas.

N॰12 FINOCHIARO, Alejandro. UBA contra Estado Nacional: un estudio de caso sobre la autonomía universitaria. Junio de 2004; 17 páginas.

$N^{\circ} 13$ KESSLER, Gabriel. Trayectorias escolares de jóvenes que cometieron delitos contra la propiedad con uso de violencia. Noviembre de 2004; 26 páginas. 
$N^{\circ} 14$ PALAMIDESSI, Mariano. El cambio del currículum para la escuela primaria a lo largo de un siglo (1880-1980). Noviembre de 2004; 31 páginas.

N॰15 CARLI, Sandra. Infancia, Cultura y Educación en las décadas del 80 y 90 en Argentina. Marzo de 2005; 17 páginas.

$N^{\circ} 16$ RAVELA, Pedro. Estudio de los factores institucionales y pedagógicos que inciden en los aprendizajes en escuelas primarias de contextos desfavorecidos en Uruguay; Junio de 2005; 39 páginas.

N¹7 SOSA ESCUDERO, Walter. Aproximaciones económicas y econométricas para la problemática educativa; Julio de 2005; 22 páginas.

N¹8 CAIMARI, Lila. Usos de Foucault en la investigación histórica; Octubre de 2005; 22 páginas.

N¹9 CARLINO, Paula. La escritura en la investigación; Marzo de 2006; 38 páginas.

$\mathrm{N}^{\circ} 20 \mathrm{BEECH}$, Jason. Las agencias internacionales, el discurso educativo y las reformas de la formación docente en Argentina y Brasil (1985-2002): un análisis comparado. Agosto de 2006; 26 páginas.

N²1 SUASNÁBAR, Claudio. Universidad e intelectuales. Educación y política en la Argentina (1955- 1976). Agosto de 2006; 16 páginas.

$N^{\circ} 22$ ALLIAUD, Andrea. La biografía escolar en el desempeño de los docentes. Febrero de 2007; 24 páginas.

N²3 SVERDLICK, Ingrid. La Investigación Educativa en el Marco de una Gestión de Gobierno en la Ciudad de Buenos Aires. Abril de 2007; 26 páginas.

$N^{\circ} 24$ DUFOUR, Gustavo. El rol de los actores de nivel intermedio en el gobierno del sistema educativo argentino. Un estudio centrado en la ciudad de Buenos Aires y la provincia de Buenos Aires. Julio de 2007; 30 páginas.

$N^{\circ} 25$ CHENG, Kai-Ming. Entendiendo la educación como una actividad humana. Septiembre de 2007; 26 páginas.

N²6 ASTIZ, María Fernanda. La socialización política de los adolescentes: un análisis comparado y trasnacional. Noviembre de 2007; 26 páginas.

$N^{\circ} 27$ BÖHMER, Martín. De la crítica a la empatía: investigación sobre la enseñanza del Derecho en la Argentina. Marzo de 2008; 16 páginas.

$N^{\circ} 28$ WILLGING, Pedro. Métodos para el análisis de interacciones virtuales. Julio de 2008; 39 páginas.

N²9 MEO, Analía. "Se hace camino al andar": investigación cualitativa, desafíos y sorpresas. El caso de un estudio etnográfico sobre clases sociales e identidades en dos escuelas en la Ciudad de Buenos Aires. Octubre de 2008; 36 páginas. 
N³0 SIMÓN, Javier. Entre la ciencia y la política: los think tanks y la producción y uso de conocimiento sobre educación en Argentina. Diciembre de 2008; 25 páginas.

N³1 DI VIRGILIO, María Mercedes. Estrategias para el análisis de las condiciones de implementación de políticas educativas: el caso del programa escuelas plurilingües. Marzo de 2009; 41 páginas.

$N^{\circ} 32$ VELEDA, Cecilia. La segregación educativa en el Conurbano Bonaerense: construcción de una problemática. Mayo de 2009; 34 páginas.

$N^{\circ} 33$ RESNIK, Julia. La trastienda de una comparación internacional. Perspectiva weberiana para el entendimiento de la globalización de la educación. Julio de 2009; 35 páginas.

$N^{\circ} 34$ BUCHBINDER, Pablo. Entre el impacto político y la historia de las universidades: una interpretación del movimiento reformista de 1918. Septiembre de 2009; 42 páginas.

$N^{\circ} 35$ MANCOVSKY, Viviana. La palabra del maestro: un estudio descriptivo y comprensivo de los juicios de valor en la interacción de la clase. Diciembre de 2009; 39 páginas.

N³6 SCHRIEWER, Jürgen. "Beruf", "vocación", "profesión" o modelos de interpretación equivalentes: representaciones simbólicas y organizaciones sociales. Febrero de 2010; 30 páginas.

N³7 AUGUSTOWSKY, Gabriela. Las paredes del aula. El registro fotográfico en la investigación educativa. Octubre de 2010; 43 páginas.

$\mathrm{N}^{\circ} 38 \mathrm{BEECH}$, Jason. Migraciones, políticas educativas y experiencias escolares: el caso de los inmigrantes latinoamericanos en Madrid y Buenos Aires. Junio de 2011; 39 páginas.

$N^{\circ} 39$ BENAVOT, Aaron. Hacer investigación comparativa en educación mediante el uso de bases de datos de fuentes históricas. Agosto de 2011; 32 páginas.

N`40 GLEYSE, Jacques. Las concepciones del cuerpo en los manuales escolares franceses de Moral e Higiene (1880 - 1975). El verbo y la carne. Octubre de 2011; 36 páginas. 